\title{
Estudo comparativo da resistência adesiva da interface resina/braquete, sob esforços de cisalha- mento, empregando três resinas compostas e três tipos de tratamento na base do braquete*
}

\author{
Adriano Lia Mondelli**, Marcos Roberto de Feitas ${ }^{\star \star \star}$
}

Resumo

Objetivo: considerando que, até o momento, a união braquete/resina é conseguida mecânica e quimicamente, esse estudo propôs avaliar: 1) a eficiência da metodologia empregada para avaliação da força de união da interface resina/braquete; 2) a resistência adesiva da interface resina/ braquete sob esforços de cisalhamento, empregando três marcas comerciais de resina composta (Concise ortodôntico, Transbond-XT e Filtek-Z-250); 3) o efeito, nesta resistência adesiva, do jateamento com óxido de alumínio, aplicado na base do braquete metálico, associado ou não ao sistema adesivo resinoso dentário. Metodologia: para avaliar a união adesiva, especificamente na interface resina/braquete, empregou-se uma máquina universal de ensaios e o teste preconizado foi o de cisalhamento. Resultados e Conclusões: após análise estatística (análise de Variância e, posteriormente, teste de Tukey) e discussão dos resultados, conclui-se que: a ocorrência de 12,5\% de fraturas coesivas pode ser considerada mínima, indicando que a metodologia empregada pode ser considerada confiável para avaliar especificamente a força de união da interface resina/braquete; em relação aos tipos de materiais empregados, sem nenhum tratamento prévio, as resinas compostas Concise ortodôntico, Transbond-XT e Filtek-Z-250 apresentaram valores similares de resistência adesiva sob esforços de cisalhamento; os tratamentos que incluíam a aplicação do adesivo específico, com ou sem jateamento com óxido de alumínio na base do braquete, foram mais efetivos para a resina composta Concise ortodôntico, quando comparados ao seu grupo controle; os tratamentos de jateamento com óxido de alumínio, associado ou não ao adesivo específico na base do braquete, foram mais efetivos estatisticamente para a resina composta Transbond-XT, quando comparados ao seu grupo controle; para a resina composta Filtek-Z-250, quando utilizado o adesivo Single Bond na base do braquete, associado ou não ao jateamento com óxido de alumínio, houve uma queda dos valores de resistência ao cisalhamento. O tratamento com jateamento de óxido de alumínio na base dos braquetes melhorou todos os valores de adesividade para todos os materiais de colagem utilizados nesta pesquisa.

Palavras-chave: Colagem. Resina composta. Cisalhamento.

* Tese apresentada à Faculdade de Odontologia de Bauru - Universidade de São Paulo, como parte dos requisitos para a obtenção do título de Doutor em Odontologia, área de Ortodontia.

** Doutor em Ortodontia pela Faculdade de Odontologia de Bauru FOB-USP. Mestre em Dentística - opção Materiais Dentários - pela Faculdade de Odontologia de Bauru FOB-USP. Professor do mestrado profissionalizante em Odontologia da UVA - Universidade Veiga de Almeida / Rio de Janeiro. Professor Adjunto no departamento de Ortodontia da Faculdade de Odontologia da UVA - Universidade Veiga de Almeida / Rio de Janeiro.

*** Professor Doutor do Departamento de Odontopediatria, Ortodontia e Saúde Coletiva da Faculdade de Odontologia de Bauru e orientador da tese. 


\section{INTRODUÇÃO}

Nos últimos anos, o grande avanço na área científica alcançado pela tecnologia trouxe inúmeros benefícios, refletindo-se intensamente na Odontologia. Inúmeras pesquisas fizeram surgir novas técnicas e materiais, que resultaram no aprimoramento e simplificação dos procedimentos clínicos. $\mathrm{Na}$ Ortodontia, desde o início do emprego da aparatologia fixa, havia uma incerteza com relação à fixação e estabilidade dos acessórios nos dentes.

Pesquisando um método para aumentar a adesão de materiais acrílicos restauradores às superfícies de esmalte previamente tratadas com solução ácida, Buonocore ${ }^{5}$, em 1955, indiretamente proporcionou um grande impulso à fixação direta de braquetes sobre a superfície do esmalte. Considerou que uma das grandes falhas das restaurações era a falta de adesividade às estruturas dentárias e que, se tal capacidade fosse desenvolvida, muitas vantagens seriam obtidas, como a diminuição da necessidade de retenção e forma de resistência em preparos cavitários e um efetivo selamento, diminuindo a infiltração marginal. $\mathrm{O}$ autor $^{5}$ concluiu que o aumento da área obtida com o condicionamento, conseqüentemente, aumenta os valores das forças de adesão, classificando esta retenção como um fenômeno puramente físico.

Apesar dos principais fatores no sucesso de qualquer terapia ortodôntica ainda serem o diagnóstico e o plano de tratamento, o emprego do sistema adesivo odontológico (ataque ácido + adesivo + resina composta) na colagem ortodôntica diretamente sobre a superfície dentária foi a técnica que revolucionou o tratamento com aparelhos ortodônticos fixos.

As vantagens da colagem direta em relação à bandagem são inúmeras como, por exemplo, a eliminação de algumas fases do tratamento (bandagem e redução de diastemas), o que economiza tempo, além de reduzir outros aspectos inconvenientes, como o comprometimento da estética, o surgimento de manchas brancas no esmalte e, con- seqüentemente, o aparecimento clínico das lesões de cárie e a instalação de inflamações gengivais, devido ao acúmulo de retenção de placas por bandas incorretamente adaptadas nas áreas cervicais ${ }^{4,12}$.

A maioria dos estudos que utilizaram acessórios metálicos relata que o local onde, normalmente, ocorre a fratura na ligação acessório/resina/dente é na interface acessório/resina, devido à fraca união adesiva existente nesta área. Muitos aperfeiçoamentos foram desenvolvidos, na tentativa de melhorar essa ligação, como a modificação no desenho das bases, seja com telas ${ }^{15,17}$, perfurada $^{15}$ ou com ranhuras ${ }^{2}$ e, mais recentemente, o jateamento das bases dos braquetes ${ }^{14,16}$, aplicando outros agentes de ligação e outros tipos de resina ${ }^{3}$. Apesar de todos estes esforços, esta interface adesiva continua sendo crítica, em termos de resistência e durabilidade da ligação no ambiente agressivo bucal.

Há pouco tempo, foi introduzido no arsenal odontológico um dispositivo especial (condicionador micromecânico Microetcher), que acoplado ao equipo odontológico possibilita o ja-

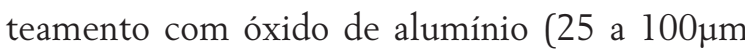
de diâmetro) das superfícies dentárias ou metálicas, diretamente na boca. Este jateamento ou condicionamento foi primeira e especialmente indicado para reparo de restaurações metalocerâmicas e metaloplásticas, porque possibilitava a silanização e ligações da resina composta à liga metálica. Posteriormente, seu uso foi estendido ao selamento de cicatrículas e fissuras, reparos de restaurações de resina composta ou de porcelana e, atualmente, para tornar mais reativas as superfícies de esmalte nas grandes restaurações adesivas. Recentemente o jateamento das bases dos braquetes foi sugerido por alguns autores ${ }^{14,16}$ e associado com outros agentes de ligações ${ }^{3}$. Todavia, ainda faltam pesquisas controladas que informem, com metodologia corretamente estabelecida, se realmente o jateamento da base do braquete, individualmente ou associado com outros agentes de ligação, aumenta ou não a resis- 
tência adesiva na interface resina/braquete.

Com base nas pesquisas, observações clínicas e opiniões de vários autores, que constam da literatura especializada, e na hipótese aventada na introdução, de que a união da resina/braquete é o elo mais frágil da resistência de colagem ortodôntica, decidiu-se avaliar:

a) a eficiência da metodologia empregada para avaliação da força de união da interface resina/ braquete.

b) a resistência adesiva da interface resina/braquete, sob esforços de cisalhamento, empregando três tipos de resina composta de mesma marca comercial;

c) o efeito, nessa resistência, da aplicação de sistema adesivo específico, do jateamento com óxido de alumínio feito sobre a base do braquete metálico, associado ou não ao sistema adesivo resinoso dentário.

\section{MATERIAL E MÉTODOS \\ Confecção dos corpos-de-prova}

Para a confecção dos corpos-de-prova foi seccionado um cano de PVC cilíndrico de $3 / 4$ de polegada, obtendo-se anéis com $3 \mathrm{~cm}$ de altura, para servirem como matrizes, possibilitando a formação de cilindros de resina. Em cada anel-matriz de PVC foram feitos internamente, com broca esfé-

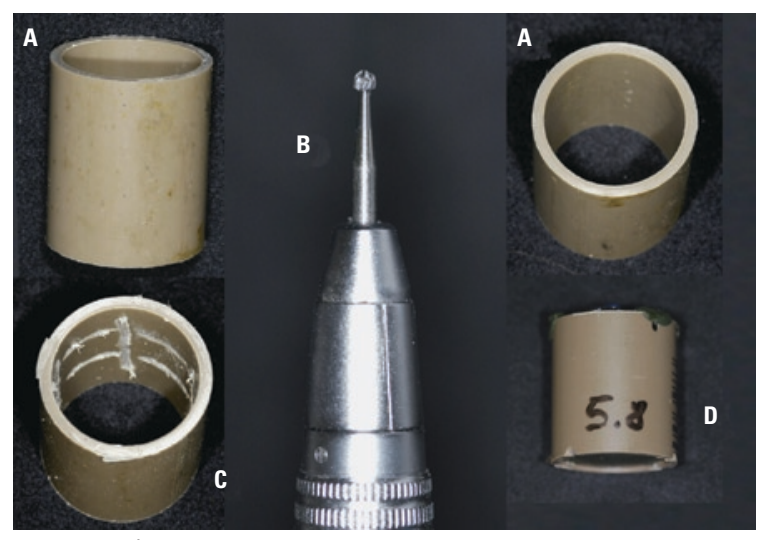

FIGURA 1 - A) Anel de PVC com 3cm de altura e 3/4 de polegada de diâmetro ou luz; B) broca esférica acoplada à peça de mão; C) sulcos retentivos internos realizados com broca esférica; $\boldsymbol{D})$ identificação dos espécimes com caneta de ponta porosa, onde 5 corresponde ao grupo experimental com resina Transbond XT e 8 ao tipo de tratamento aplicado na base do braquete. rica, sulcos circulares para reter a resina epóxica que seria vertida posteriormente dentro do anelmatriz (Fig. 1).

Para realização do presente trabalho foram utilizados 120 braquetes ortodônticos de aço inoxidável (Andrews 0,022" x 0,030" código U1L 281002 - KIRIUM Abzil Indústria e comércio Ltda. - São José do Rio Preto, SP - Brasil).

Os braquetes foram fixados em um fio retangular de aço inoxidável de 0,019" x 0,025" e amarrados firmemente com fio de aço de $0,010 "$ ". O objetivo dessa fixação foi dar estabilidade e retenção do conjunto braquetes-fio à resina epóxica que seria vertida no interior do anel-matriz de PVC. Cada bloco de resina incluída no anel de PVC recebeu dois braquetes amarrados a dois fios de aço, que eram por sua vez fixados pelas extremidades à borda do anel com resina acrílica ativada quimicamente. Isto foi necessário para que, no momento do ensaio, não ocorresse deslocamento do corpode-prova (Fig. 2).

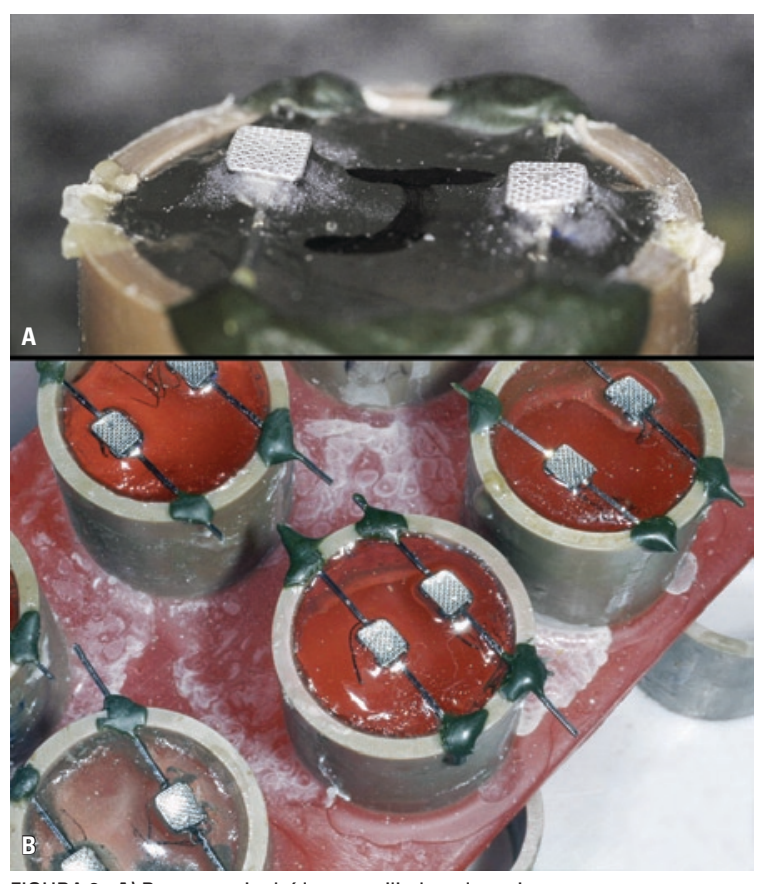

FIGURA 2 - A) Braquetes incluídos nos cilindros de resina por sua parte externa ou vestibular (aletas e ranhuras), mantendo a base livre de contaminação pela resina; B) notar a fixação dos fios com godiva de alta fusão nas bordas dos anéis. 
Os corpos-de-prova foram divididos em 12 grupos, com 10 espécimes para cada um deles.

Previamente aos tratamentos experimentais e à inserção da resina composta, todas as bases dos braquetes foram limpas "profilaticamente" com pasta de pedra-pomes e água, aplicada com escova Robson tipo pincel, girando em micromotor à baixa velocidade.

\section{Grupo 1 - Concise ortodôntico (sem tratamen- to na base do braquete / grupo controle)}

$\mathrm{O}$ que caracterizou o grupo controle desta resina foi não ter sido realizado nenhum tipo de tratamento na base do braquete, antes da aplicação da resina composta Concise ortodôntico para colagem. Esta resina, por ser de ativação química, é constituída por uma pasta base A, composta por Bis-glicidil-metacrilato (Bis-GMA), trietileno-glicol-dimetacrilato (TEGDMA) e quartzo tratado com silano, e uma pasta catalisadora B, composta por Bis-glicidil-metacrilato (Bis-GMA), trietilenoglicol-dimetacrilato (TEGDMA) e quartzo tratado com silano e peróxido de benzoíla (Fig. 3). Duas porções com quantidades iguais da pasta A e pasta B foram colocadas no bloco de papel, para mistura, e espatuladas durante 20 segundos, seguindo a recomendação do fabricante, e inseridas na base do braquete com espátula específica $\mathrm{n}^{\circ} 1$ (Suprafill S.S. White) para resina composta (Fig. 4A, B, C, D). A resina composta, depois de adaptada na base do braquete, foi modelada com a espátula até formar um platô saliente (Fig. 4E), para o apoio e adaptação da ponta biselada que transmite o carregamento da máquina universal de ensaios ao corpo-de-prova, provocando esforços de cisalhamento na junção interfacial base do braquete/união adesiva. Para todos os espécimes dos 12 grupos experimentais de colagem a resina composta foi modelada com a mesma morfologia ilustrada nas figuras 4C, D, E.

Terminadas a inserção e a modelagem da resina composta, eram aguardados 10 minutos para completa polimerização, antes que os corpos-de- prova devidamente identificados fossem armazenados em um recipiente com água deionizada e levados ao interior de uma estufa à temperatura de $37 \pm 2^{\circ} \mathrm{C}$, durante 48 horas, até o momento do teste de cisalhamento.

\section{Grupo 2 - Concise ortodôntico (ataque ácido + resina fluida + resina composta)}

Antes da inserção da resina composta Concise ortodôntico, foi realizado um condicionamento na base do braquete, com ácido fosfórico a 37\% (3M ESPE), do conjunto Concise ortodôntico, por 30 segundos (Fig. 5A, B, D); depois a base do braquete foi lavada com spray ar/água em abundância, durante 20 segundos; após a superfície foi seca com jatos de ar comprimido, livre de óleo e água. Quantidades iguais da resina A e resina B, do adesivo dentário ou resina fluida foram colocadas no casulo e homogeneizadas seguindo a recomendação dos fabricantes, durante 5 a 10 segundos, e aplicadas na base do braquete com o auxílio de um minipincel ou ponta infusora (Fig. 5C, E).

A composição adesiva da resina fluida Concise ortodôntico é, segundo o fabricante, a seguinte: Resina A - Bis-glicidil-metacrilato (Bis-GMA), trietileno-glicol-dimetacrilato (TEGDMA); Resina B Bis-glicidil-metacrilato (Bis-GMA), trietileno-glicoldimetacrilato (TEGDMA) e peróxido de benzoíla.

A pasta A mais a pasta B foram dosificadas e colocadas no bloco de mistura, espatuladas e inseridas na base do braquete, seguindo a mesma seqüência e configuração do grupo 1. As demais fases também foram iguais às do grupo 1 .

\section{Grupo 3 - Concise ortodôntico (jato de óxido de alumínio + resina composta)}

Antes da inserção da resina composta Concise ortodôntico, foi realizado um jateamento por 10 segundos na base do braquete, com óxido de alumínio de partículas de $50 \mu \mathrm{m}$, utilizando um dispositivo apropriado, denominado Microetcher, acoplado ao equipo odontológico (Fig. 6B). A pressão de jateamento (80 libras) foi controlada 
por um barômetro colocado na entrada de ar comprimido do equipo odontológico.

Depois do jateamento, os braquetes foram lavados com spray ar-água, para a eliminação de

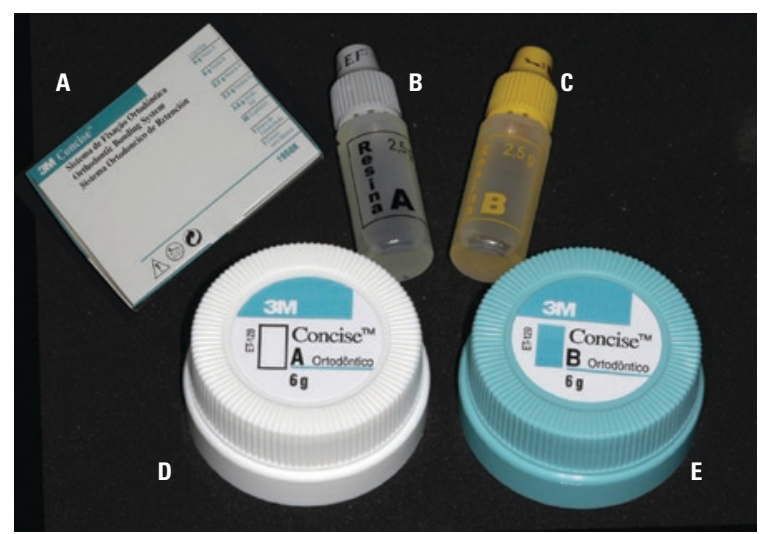

FIGURA 3 - A) Conjunto da resina composta Concise ortodôntico; B) resina fluida $A ; C)$ resina fluida $B ; D$ ) resina composta $A ; E$ ) resina composta $B$. qualquer resíduo que pudesse alterar a adesão, e depois secos completamente. Logo após esta fase, a pasta $A$ mais a pasta $B$ foram dosificadas em quantidades iguais e colocadas no bloco de mistura, espatuladas e inseridas na base do braquete, seguindo a mesma seqüência do grupo 1. Portanto, após o jateamento, neste grupo não foi aplicado o adesivo. As fases subseqüentes seguiram as adotadas nos grupos 1 e 2 .

\section{Grupo 4 - Concise ortodôntico (jato de óxido de alumínio + ataque ácido + resina fluida + resina composta)}

Este foi o último grupo da resina composta Concise ortodôntico, no qual foram efetuados dois tratamentos prévios, antes da aplicação da resina. Inicialmente, foi realizado jateamento, por

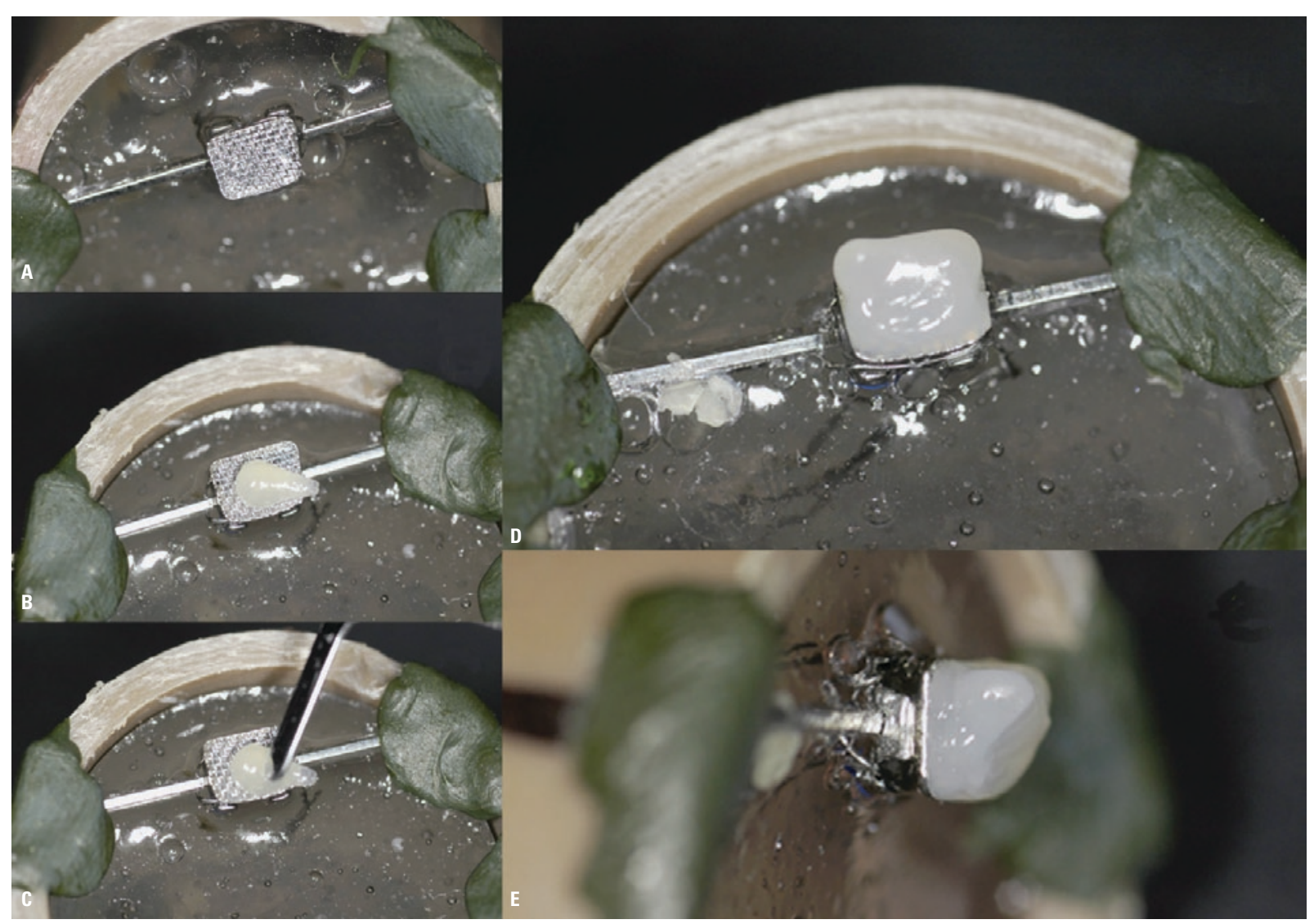

FIGURA 4 - Aplicação da resina Concise ortodôntico de ativação química: A) braquete fixado em posição de colagem; B) colocação do primeiro incremento de resina; C, D) conformação da resina composta acompanhando o desenho da base do braquete; E) vista lateral do platô de resina composta para permitir os esforços de cisalhamento. 
10 segundos, com óxido de alumínio de partículas de $50 \mu \mathrm{m}$ na base do braquete, utilizando Microetcher, do modo como foi feito para o grupo 2 (Fig. 6). Em seguida, foram realizados o condicionamento ácido, a aplicação do adesivo e da resina composta, nas mesmas condições descritas para o grupo 2, e depois armazenados em estufa por iguais períodos e temperatura.

\section{Grupo 5 - Transbond XT (sem tratamento na base do braquete / grupo controle)}

Também neste grupo controle não foi realizado nenhum tipo de tratamento na base do braquete "colado" com a resina Transbond XT: cada grupo experimental desta condição em que se empregou

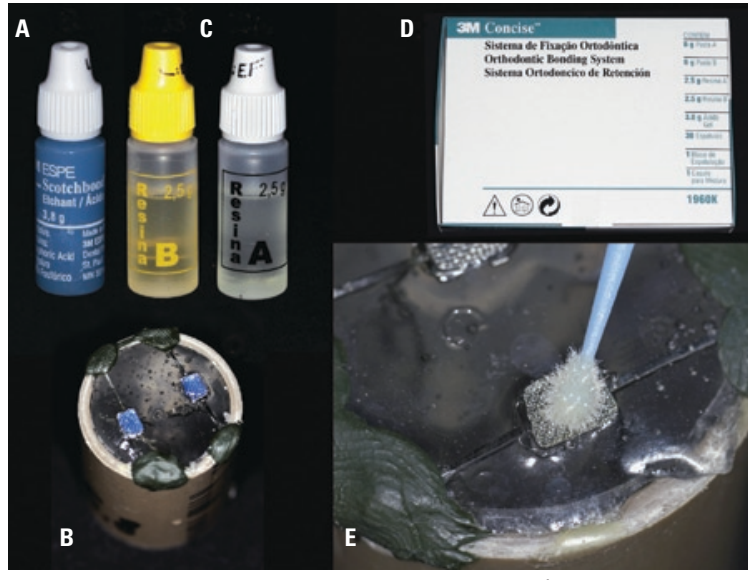

FIGURA 5 - Sistema adesivo do Concise ortodôntico: - A) frasco ou recipiente de plástico que contém o ácido fosfórico a 37\% (3M ESPE); B) ácido fosfórico a $37 \%$ aplicado nos braquetes; C) resina fluida - Concise ortodôntico; D) caixa do produto Concise ortodôntico; E) aplicação da resina fluida Concise ortodôntico com minipincel ou ponta infusora de plástico no braquete.

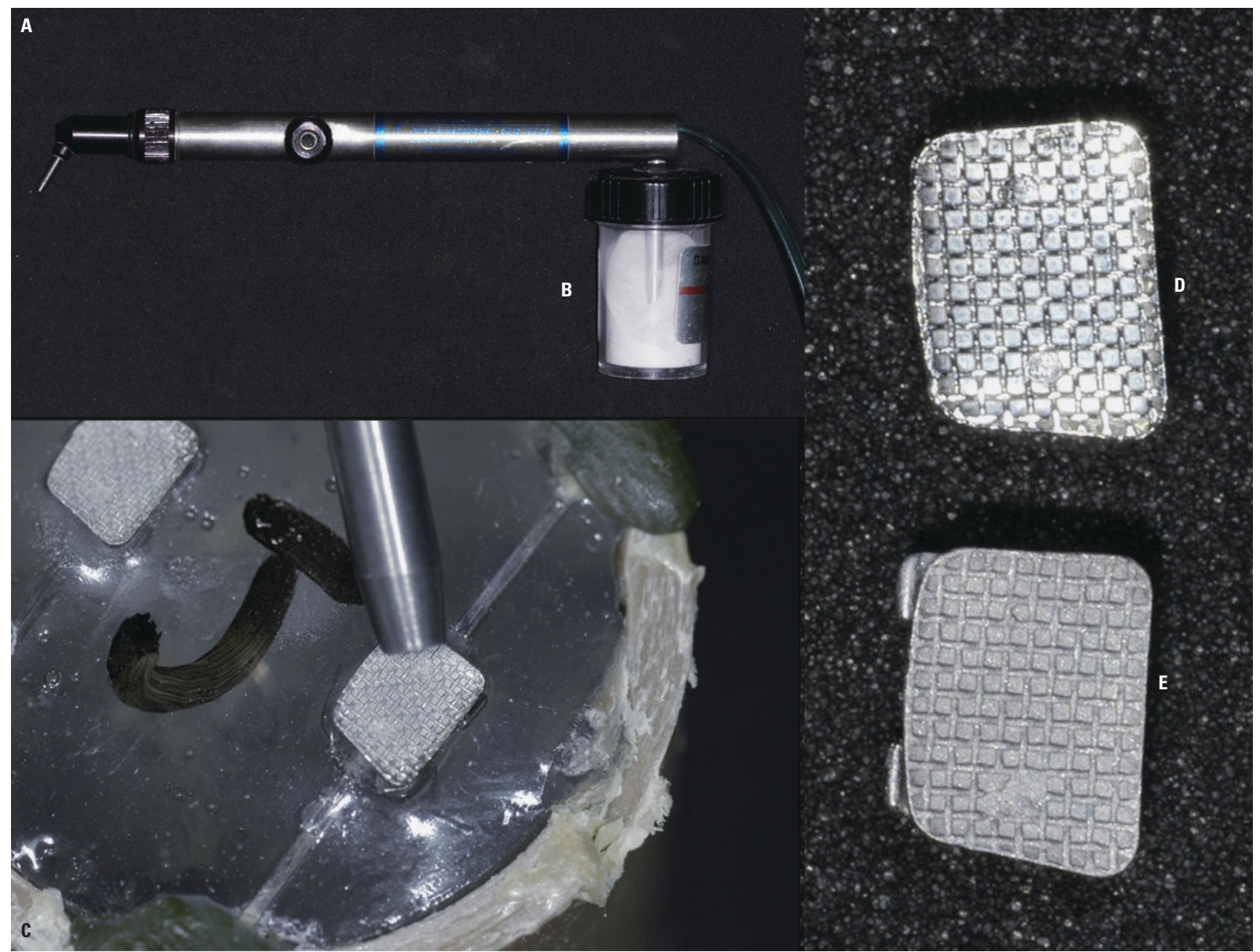

FIGURA 6 - A) Dispositivo de jateamento “Microetcher"; B) reservatório de partículas de óxido de alumínio com 50 $\mu$ m; C) braquete sendo jateado; D) braquete não jateado; E) braquete após jateamento. Notar a eliminação do brilho da base do braquete (D); após o jateamento com óxido de alumínio (E). 


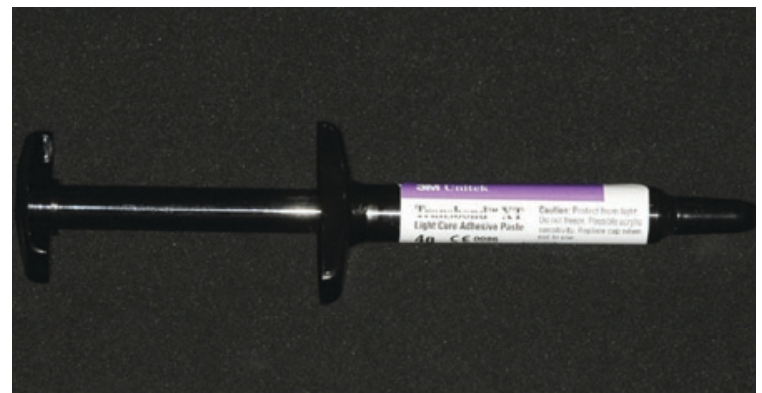

FIGURA 7 - Bisnaga contendo a resina composta Transbond XT.

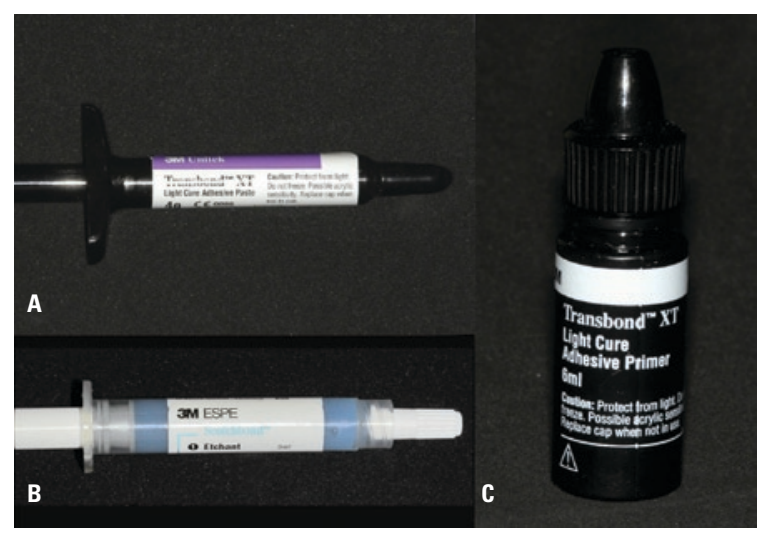

FIGURA 8 - Conjunto do produto Transbond XT: A) bisnaga contendo a resina composta Transbond XT; B) seringa de ácido fosfórico a 37\% 3M ESPE; C) resina fluida do conjunto Transbond XT.

a resina composta Transbond XT foi também composto por 10 espécimes. A resina composta Transbond XT (Fig. 7) contém, segundo seu fabricante: Sílica, Bis-Gma silano, n-dimetilbenzocaina, hexaflúor-fosfato. À exceção do sistema de polimerização, a inserção, conformação do platô, tempo e temperatura de armazenagem foram similares ao grupo 1. Após a inserção, a resina composta Transbond XT foi polimerizada empregando-se um fotopolimerizador (Curing Light XL 1500, modelo 5518AA, 3M), por período de polimerização de 60 segundos para cada espécime.

\section{Grupo 6 - Transbond XT (ataque ácido + resi- na fluida + resina composta)}

Neste grupo, de modo similar ao grupo 2, a base do braquete foi condicionada com ácido fosfórico a 37\% (3M ESPE) (Fig. 8A, B), por 30 segundos, lavada e seca com ar. Sobre a superfície condicionada da base do braquete foi colocada uma fina camada de resina fluida do conjunto Transbond XT. A composição do adesivo do Transbond XT é, segundo o fabricante, a seguinte: Trietileno-glicol-dimetacrilato, Bis-GMA (Fig. $8 C)$. Foi aplicado com o auxílio de um minipincel e polimerizado por 20 segundos, empregando-se um fotopolimerizador (Curing Light XL 1500, modelo 5518AA, 3M).

O processo de inserção, confecção do platô e polimerização da resina composta foi semelhante ao grupo 5. O período de 48 horas de armazenagem em um recipiente com água deionizada, no interior de uma estufa a $37 \pm 2^{\circ} \mathrm{C}$, foi também observado neste grupo experimental.

\section{Grupo 7 - Transbond XT (jato de óxido de alu- mínio + resina composta)}

Neste grupo foi realizado apenas um tratamento prévio (jateamento com óxido de alumínio de

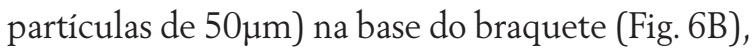
utilizando-se o dispositivo Microetcher. Pode-se notar nas figuras 6D e 6E a eliminação do brilho da base do braquete após o jateamento com óxido de alumínio.

Depois do jateamento, os braquetes foram lavados abundantemente, por 30 segundos, com água corrente, para a eliminação de qualquer resíduo que pudesse alterar a adesão, e depois secos completamente. A resina foi inserida, modelada, polimerizada e armazenada, semelhantemente a todos os grupos anteriores.

\section{Grupo 8 - Transbond XT (jato de óxido de alu- mínio + ataque ácido + resina fluida + resina composta)}

Este constitui o último grupo da resina Transbond XT e, de modo similar ao grupo 4, a base do braquete recebeu dois tratamentos condicionadores prévios: o jateamento com óxido de alumínio por 10 segundos e o ataque ácido com ácido fosfórico a 37\% por 30 segundos. Após esses dois tratamentos, uma fina camada de resina fluida, do conjunto 
Transbond XT, foi aplicada sobre a superfície condicionada da base do braquete, com o auxílio de um minipincel, e polimerizada por 20 segundos, empregando-se um fotopolimerizador (Curing Light XL 1500, modelo 5518AA, 3M).

A inserção, modelagem do platô, polimerização da resina composta Transbond XT e armazenagem subseqüente, por igual período e temperatura, foram iguais aos demais grupos.

\section{Grupo 9 - Filtek Z-250 (sem tratamento na base do braquete / grupo controle)}

Neste grupo não foi realizado nenhum tipo de tratamento na base do braquete, servindo como controle para os ensaios que seriam realizados após a "colagem" com a resina composta Filtek ${ }^{\mathrm{TM}}$ Z-250. Essa resina (Fig. 9) é composta basicamente por carga inorgânica de Zircônia e Sílica; a quantidade de partículas inorgânicas é 60\% em volume, com tamanhos de partículas variáveis entre $0,01 \mu \mathrm{m}$ e $3,5 \mu \mathrm{m}$ e a parte orgânica contém as resinas Bis-Gma, UDMA e Bis-Ema. A resina foi inserida, modelada e polimerizada na base do braquete, semelhantemente a todos os grupos anteriores (Fig. 4A, B, C, D). Após a inserção, a resina composta Filtek ${ }^{\mathrm{TM}} \mathrm{Z}-250$, por ser fotoativada, foi polimerizada com o aparelho Curing Light XL 1500 (modelo 5518AA, 3M) por um período de 60 segundos para cada espécime.

Após a polimerização da resina composta, eram aguardados 10 minutos antes que os corpos-de-prova fossem armazenados em um recipiente com água deionizada e levados, devidamente identificados, ao interior de uma estufa, à temperatura de $37 \pm 2^{\circ} \mathrm{C}$, durante 48 horas, até o momento dos testes de cisalhamento.

\section{Grupo 10 - Filtek ${ }^{\mathrm{TM}}$ Z-250 (ataque ácido + re- sina fluida + resina composta)}

Este grupo, semelhantemente aos grupos 2 e 6 , recebeu um tratamento prévio na base do braquete antes da inserção da resina; esse tratamento prévio foi um ataque químico, com ácido fosfóri-

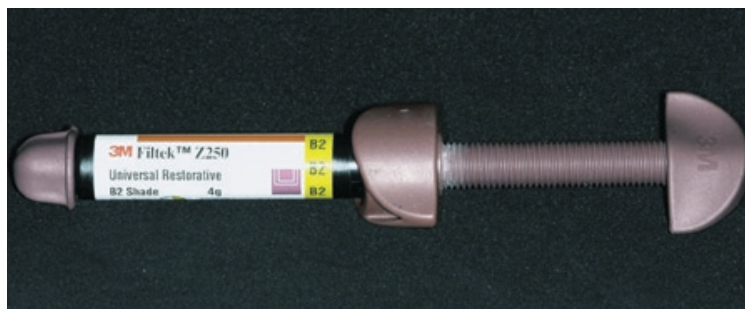

FIGURA 9 - Forma de apresentação, em bisnaga, da resina composta Filtek Z-250.

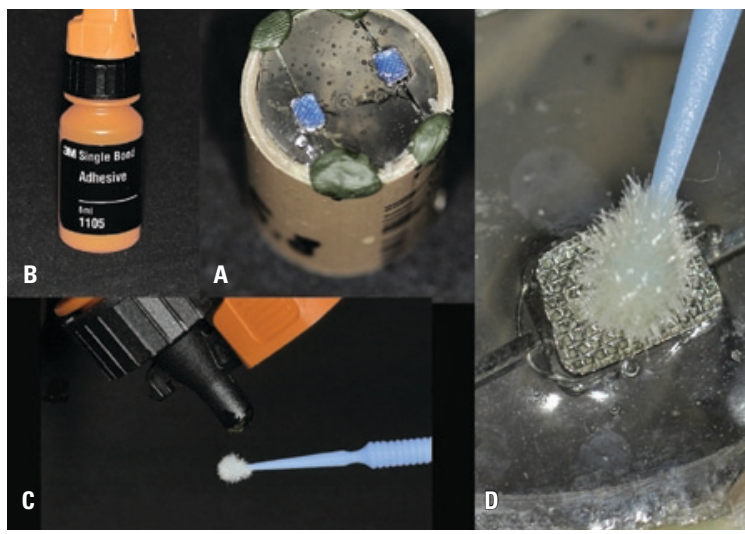

FIGURA 10 - A) Ácido fosfórico a 37\% na forma de gel, aplicado sobre a base do braquete, promovendo o condicionamento químico; B) resina fluida Single Bond em frasco único ou monocomponente; C) resina fluida sendo gotejada no minipincel; D) ponta infusora aplicando a resina fluida na base do braquete.

co a 37\% (3M ESPE), por 30 segundos (Fig. 10A, B). Após lavagem e secagem da base do braquete, uma fina camada de resina fluida Single Bond, composta por HEMA 2-hidroxietilmetacrilato e acrilatos (Fig. 10B), foi aplicada com um minipincel ou ponta infusora, sobre a superfície condicionada da base do braquete, e polimerizada por 20 segundos, empregando-se um fotopolimerizador (Curing Light XL 1500 (modelo 5518AA, 3M) (Fig. 10A, B, C, D).

Após a fotopolimerização da resina fluida Single Bond, a resina composta Filtek ${ }^{\mathrm{TM}} \mathrm{Z}-250$ foi inserida e modelada, formando um platô na base do braquete, fotopolimerizada e armazenada, nas mesmas condições dos demais grupos experimentais, até o momento dos ensaios de cisalhamento na máquina universal de ensaios. 


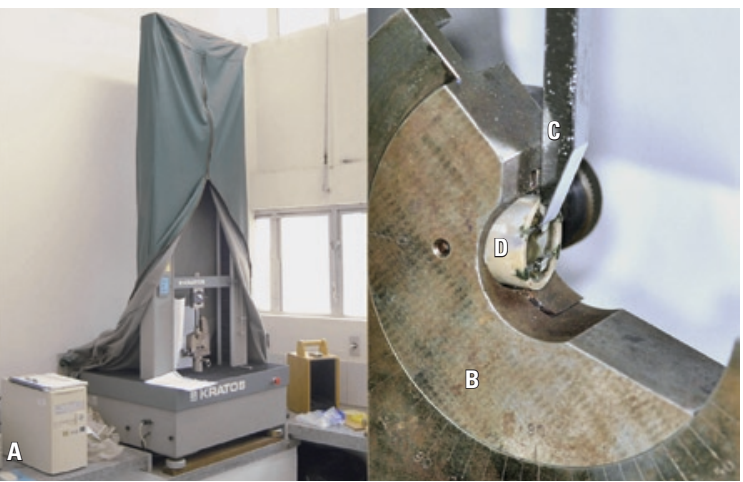

FIGURA 11 - A) Vista geral da máquina universal de ensaios Kratos; B) dispositivo com o corpo-de-prova; C) ponta aplicadora de pressão biselada; D) posicionada junto à base do braquete.

\section{Grupo 11 - Filtek ${ }^{\mathrm{TM}}$ Z-250 (jato de óxido de alumínio + resina composta)}

Neste grupo, à semelhança dos grupos 3 e 7, foi realizado apenas um tratamento na base do braquete antes da inserção da resina composta Filtek $^{\mathrm{TM}} \mathrm{Z}-250$, ou seja, o jateamento por 10 segundos com óxido de alumínio de partículas de $50 \mu \mathrm{m}$, utilizando o dispositivo Microetcher. Após o jateamento com óxido de alumínio, limpeza com água e secagem com ar, a resina composta Filtek $^{\mathrm{TM}} \mathrm{Z}-250$ foi inserida diretamente na base do braquete, sem aplicação de adesivo, esculpida formando um platô, polimerizada e armazenada nas mesmas condições dos grupos anteriores, até o momento dos testes de cisalhamento na máquina universal de ensaios.

\section{Grupo 12 - Filtek ${ }^{\mathrm{TM}}$ Z-250 (jato de óxido de alumínio + ataque ácido + resina fluida + resi- na composta)}

Os mesmos procedimentos empregados para o grupo 8 foram aplicados, diferindo apenas no tipo de resina, sendo utilizada a resina para restauração Filtek $^{\mathrm{TM}} \mathrm{Z}-250$.

\section{Realização dos ensaios}

Decorridas 48 horas da inserção da resina composta nos corpos-de-prova, estes foram colocados em um dispositivo apropriado ao ensaio ${ }^{7}$.

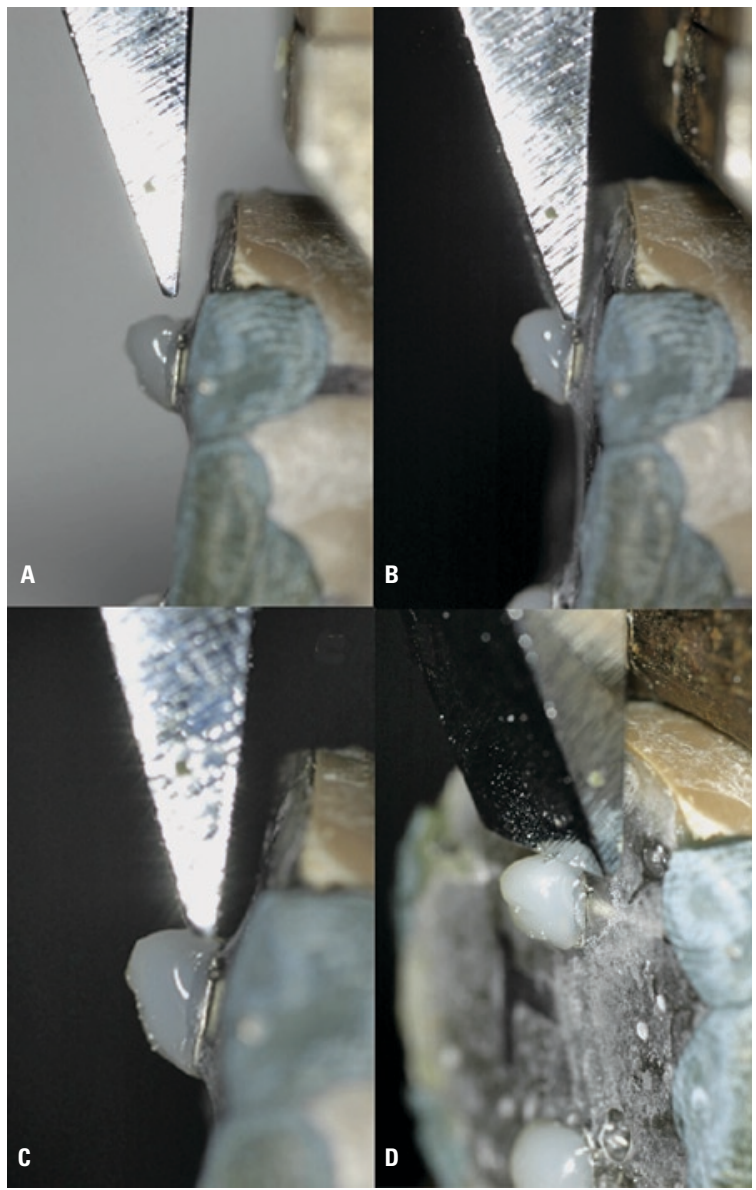

FIGURA 12 - A) Ponta aplicadora de carregamento compressivo junto ao corpode-prova, adaptado na interface (B, C); D) momentos antes da ruptura da ligação adesiva da interface resina/base do braquete.

O dispositivo era adequadamente fixado à base inferior de uma máquina universal de ensaios (Máquina de Ensaios KRATOS, modelo K2000 MP número de série: m970201 220 volts Kratos equipamentos industriais LTDA-SP) (Fig. 11).

Uma ponta de aço inoxidável biselada, com $1 \mathrm{~mm}$ de altura e $10 \mathrm{~mm}$ de largura do gume ativo, era fixada à célula de carga $\mathrm{n}^{\circ} 2$ acoplada à máquina de ensaios, posicionada e apoiada no platô de resina composta, para testar a interface de união entre a base do braquete e a resina composta, como pode ser observado na figura 12. A máquina era então acionada, à velocidade de $0,5 \mathrm{~mm}$ por minuto, no sentido de compressão, desenvolvendo-se, assim, uma tensão de cisalhamento na in- 
terface base do braquete/resina, até o momento da fratura ou rompimento da união adesiva. Os valores eram registrados diretamente $\mathrm{em} \mathrm{kgf} / \mathrm{cm}^{2}$ no monitor digital da máquina de ensaios.

\section{RESULTADOS}

Os valores originais registrados na máquina de ensaios em $\mathrm{kgf} / \mathrm{cm}^{2}$, quando da descolagem na interface resina/base dos braquetes, foram transformados em $\mathrm{kgf} / \mathrm{mm}^{2}$, para melhor entendimento, praticidade de comunicação e divulgação entre os ortodontistas. Utilizou-se como referência para esta transformação a base do braquete da Abzil código U1L-281-002X, cuja área de colagem linear é de $12,5 \mathrm{~mm}^{2}$.

Os resultados aqui encontrados demonstram que todos os tipos de tratamento utilizados, até mesmo aqueles que diminuíram as médias de resistência adesiva em relação aos seus respectivos controles, estão situados em uma faixa de valores que possibilita sua utilização clínica. Isto pode ser comprovado pelo trabalho de Kydd et al. ${ }^{9}$, que encontraram valores suficientemente fortes para suportar as forças exercidas pelo arco sobre os dentes durante o tratamento ortodôntico e porque as forças mínimas de 6 a $8 \mathrm{MPa}$, e de $0,140 \mathrm{~kg} / \mathrm{mm}^{2}$, foram superadas em suas experimentações.

$\mathrm{Na}$ tabela 1 há duas colunas, uma que representa os valores em $\mathrm{kgf} / \mathrm{mm}^{2}$ e outra que representa os valores adaptados ao braquete utilizado nesta pesquisa; isso foi realizado porque quanto maior a área da base do braquete maior a força necessária para romper a união e também porque existe uma grande variabilidade de braquetes com bases de diferentes tamanhos.

A análise de variância a dois critérios de classificação, aplicada aos valores de resistência adesiva (Tab. 2), mostrou a existência de diferença estatisticamente significante entre as condições principais resina composta e tratamento na base do braquete. Verifica-se também a ocorrência de interação, devida à interferência não homogênea das variáveis introduzidas (tratamentos) nos fatores principais, ora aumentando ora diminuindo a resistência adesiva.

Para complementar a análise estatística, desde que a análise de variância demonstrou existir diferença estatisticamente significante entre os fatores principais e interação, foi aplicado o teste de Tukey, que permitiu comparar diferenças individuais entre os grupos.

O teste de Tukey demonstrou, com índice de probabilidade menor que 0,05 , que realmente nem todas as variáveis produziram o mesmo efeito nas diferentes condições testadas (Tab. 3).

A comparação intragrupo dos valores obtidos com a resina Concise ortodôntico, mostrada na tabela 4, indica que o grupo 1 , que serviu como controle, igualmente aos resultados de outras pesquisas e outros autores que utilizaram o mesmo material ${ }^{1,6,10}$, teve a resistência adesiva aumentada estatisticamente quando foi usado tratamento na base (grupo 2 e 4). Pode-se notar que a utilização do adesivo Concise ortodôntico nas bases (grupo 2) aumentou a força de adesão, enquanto no grupo que recebeu apenas o jato de óxido de alumínio a diferença numérica não foi estatisticamente significante. Contudo, no grupo 4, que recebeu jato de óxido de alumínio e adesivo, observa-se a maior média de resistência adesiva de todos os tratamentos aplicados com esta resina. Pode-se inferir que esse tipo de tratamento foi o que apresentou melhor índice de aumento da retentividade da resina composta Concise ortodôntico na base do braquete. Pode-se inferir que, apesar do jateamento por si só não ter aumentado significantemente a força de adesão na interface estudada, esse tratamento não prejudicou a adesão, mas até mesmo aumentou-a aritmeticamente. Isto indica que o jato de alumínio pode, eventualmente, ser associado ao adesivo, quando o material de colagem for o Concise ortodôntico. Assim, pode-se inferir que todos os tratamentos aqui aplicados nas bases dos braquetes, para serem colados com a resina composta Concise ortodôntico, melhoraram a adesividade na interface braquete/resina. Portanto, esses tratamentos podem ser utilizados na clínica ortodônti- 
Tabela 1 - Médias de resistência adesiva sob esforços de cisalhamento para cada grupo experimental e respectivos tratamentos aplicados na base do braquete.

\begin{tabular}{|c|c|c|c|c|}
\hline número do grupo & $\begin{array}{l}\text { tratamento dado à base do braquete } \\
\text { e resina utilizada }\end{array}$ & $\begin{array}{l}\text { médias em } \\
\mathrm{kgf} / \mathrm{mm}^{2}\end{array}$ & $\begin{array}{l}\text { médias para os braquetes } \\
\text { em kgf/12,5mm }{ }^{2}\end{array}$ & d.p. \\
\hline 1 & Concise ortodôntico sem tratamento (grupo controle) & 0,263 & 3,28 & 0,0183 \\
\hline 2 & $\begin{array}{c}\text { ataque ácido }+(\operatorname{adesivo}(A)+\text { adesivo }(B)) \text { do conjunto Concise } \\
\text { ortodôntico+ Concise ortodôntico }\end{array}$ & 0,325 & 4,06 & 0,0188 \\
\hline 3 & jato de óxido de alumínio + Concise ortodôntico & 0,285 & 3,56 & 0,0155 \\
\hline 4 & $\begin{array}{l}\text { jato de óxido de alumínio + ataque ácido + (adesivo }(A)+\text { adesivo } \\
\text { (B)) do conjunto Concise ortodôntico + Concise ortodôntico }\end{array}$ & 0,337 & 4,21 & 0,0198 \\
\hline 5 & Transbond XT sem tratamento (grupo controle) & 0,278 & 3,47 & 0,0086 \\
\hline 6 & ataque ácido + adesivo do conjunto Transbond XT+ Transbond XT & 0,284 & 3,55 & 0,0172 \\
\hline 7 & jato de óxido de alumínio + Transbond XT & 0,322 & 4,02 & 0,0163 \\
\hline 8 & $\begin{array}{l}\text { jato de óxido de alumínio + ataque ácido + adesivo do conjunto } \\
\text { Transbond XT + Transbond XT }\end{array}$ & 0,307 & 3,83 & 0,0101 \\
\hline 9 & Filtek Z-250 sem tratamento (grupo controle) & 0,263 & 3,28 & 0,0197 \\
\hline 10 & ataque ácido + adesivo Single Bond + Filtek Z-250 & 0,203 & 2,53 & 0,0196 \\
\hline 11 & jato de óxido de alumínio + Filtek Z-250 & 0,269 & 3,36 & 0,0146 \\
\hline 12 & $\begin{array}{l}\text { jato de óxido de alumínio + ataque ácido + adesivo } \\
\text { Single Bond + Filtek Z-250 }\end{array}$ & 0,243 & 3,03 & 0,0174 \\
\hline
\end{tabular}

Tabela 2 - Análise de variância, a dois critérios de classificação, aplicada aos valores de resistência adesiva.

\begin{tabular}{lcccccc}
\hline & $\begin{array}{c}\text { graus de liberdade } \\
\text { (efeito) }\end{array}$ & $\begin{array}{c}\text { quadrado médio } \\
\text { (efeito) }\end{array}$ & $\begin{array}{c}\text { graus de liberdade } \\
\text { (erro) }\end{array}$ & $\begin{array}{c}\text { quadrado médio } \\
\text { (erro) }\end{array}$ & F & p \\
\hline $\begin{array}{l}\text { resina composta } \\
\text { tratamento na } \\
\text { base do braquete }\end{array}$ & 2 & 0,00421119 & 108 & 0,00027988 & 150,4639 & $0,000000^{*}$ \\
$\begin{array}{l}\text { resina composta } \\
\text { X }\end{array}$ & 3 & 0,00536736 & 108 & 0,00079880 & 19,1773 & $0,000000^{*}$ \\
$\begin{array}{l}\text { tratamento na } \\
\text { base do braquete }\end{array}$ & 6 & 0,00992533 & 108 & 0,00027988 & 35,4627 & $0,000000^{*}$ \\
\hline * & & & & & \\
\hline ifferença estatisticamente significante $(\mathrm{p}<0,01)$.
\end{tabular}

ca, quando for necessário aumentar a resistência adesiva de braquetes colados com essa resina.

Observa-se a utilização da resina composta específica para Ortodontia, Transbond XT, nos grupos controle 5 e experimentais 6,7 e 8 . A comparação intragrupo da resina Transbond XT pode ser observada na tabela 5 , onde o grupo controle 5 obteve média inferior aos demais, sendo a diferença estatisticamente significante em comparação aos grupos 7 e 8, que receberam tratamento na base. Esse fato indica que, clinicamente, o jateamento da base para utilização do Transbond XT aumenta as forças de adesão na interface resina/ braquete. Portanto, diferentemente do ocorrido com o Concise ortodôntico neste trabalho, o efeito do jateamento com óxido de alumínio, antes da colagem adesiva, foi estatisticamente significante. Por isso, verificou-se a ocorrência de interação, apontada pela análise de variância. Para este tipo de resina, o grupo 6, onde foi aplicado somente o adesivo como meio para aumentar a adesividade da interface resina/braquete, à semelhança do grupo 3, não promoveu aumento significante da força de adesão na interface estudada, mas somen- 
Tabela 3 - Teste de Tukey para comparações individuais entre os grupos.

\begin{tabular}{|c|c|c|c|c|c|c|c|c|c|c|c|c|}
\hline & grupo 1 & grupo 2 & grupo 3 & grupo 4 & grupo 5 & grupo 6 & grupo 7 & grupo 8 & grupo 9 & grupo 10 & grupo 11 & grupo 12 \\
\hline grupo 1 & & $0,000122^{*}$ & 0,105888 & $0,000122^{*}$ & 0,680172 & 0,181203 & $0,000122^{*}$ & $0,000123^{*}$ & 1,000000 & $0,000122^{*}$ & 0,999684 & 0,260997 \\
\hline grupo 2 & $0,000122^{*}$ & & $0,000122^{*}$ & 0,908902 & $0,000122^{*}$ & $0,000131^{*}$ & 1,000000 & 0,393959 & $0,000122^{*}$ & $0,000122^{*}$ & $0,000122^{*}$ & $0,000122^{*}$ \\
\hline grupo 3 & 0,105878 & $0,000148^{*}$ & & $0,000122^{*}$ & 0,996320 & 1,000000 & $0,000292^{*}$ & 0,151021 & 0,109472 & $0,000122^{*}$ & 0,511872 & $0,000126^{*}$ \\
\hline grupo 4 & $0,000122^{*}$ & 0,908902 & $0,000122^{*}$ & & $0,000122^{*}$ & $0,000122^{*}$ & 0,698070 & $0,005850^{*}$ & $0,000122^{*}$ & $0,000122^{*}$ & $0,000122^{*}$ & $0,000122^{*}$ \\
\hline grupo 5 & 0,680172 & $0,000122^{*}$ & 0,996320 & $0,000122^{*}$ & & 0,999630 & $0,000123^{*}$ & $0,007333^{*}$ & 0,689155 & $0,000122^{*}$ & 0,986596 & $0,000610^{*}$ \\
\hline grupo 6 & 0,181203 & $0,000131^{*}$ & 1,000000 & $0,000122^{*}$ & 0,999603 & & $0,000179 *$ & 0,086226 & 0,186632 & $0,000122^{*}$ & 0,671170 & $0,000122^{*}$ \\
\hline grupo 7 & $0,000122^{*}$ & 1,000000 & $0,000292^{*}$ & 0,698070 & $0,000123^{*}$ & $0,000179 *$ & & 0,671120 & $0,000122^{*}$ & $0,000122^{*}$ & $0,000122^{*}$ & $0,000135^{*}$ \\
\hline grupo 8 & $0,000123^{*}$ & 0,393959 & 0,151021 & $0,005850^{*}$ & $0,007333^{*}$ & 0,086226 & 0,671120 & & $0,000123^{*}$ & $0,000122^{*}$ & $0,000179 *$ & $0,000122^{*}$ \\
\hline grupo 9 & 1,000000 & $0,000122^{*}$ & 0,109472 & $0,000122^{*}$ & 0,689155 & 0,186632 & $0,000122^{*}$ & $0,000123^{*}$ & & $0,000122^{*}$ & 0,999131 & $0,000122^{*}$ \\
\hline grupo 10 & $0,000122^{*}$ & $0,000122^{*}$ & $0,000122^{*}$ & $0,000122^{*}$ & $0,000122^{*}$ & $0,000122^{*}$ & $0,000122^{*}$ & $0,000122^{*}$ & $0,000122^{*}$ & & $0,000122^{*}$ & 0,254159 \\
\hline grupo 11 & 0,999684 & $0,000122^{*}$ & 0,511872 & $0,000122^{*}$ & 0,986596 & 0,671120 & $0,000122^{*}$ & $0,000179 *$ & 0,999731 & $0,000122^{*}$ & & $0,035322 *$ \\
\hline grupo 12 & 0,260997 & $0,000122^{*}$ & $0,000126^{*}$ & $0,000122^{*}$ & $0,000610^{*}$ & $0,000135^{*}$ & $0,000122^{*}$ & $0,000122^{*}$ & 0,254159 & $0,000153^{*}$ & $0,035322^{*}$ & \\
\hline
\end{tabular}

* Diferença estatisticamente significante $(p<0,05)$.

Tabela 4 - Médias da resistência adesiva sob esforços de cisalhamento, obtidas com o Concise ortodôntico.

\begin{tabular}{|c|c|c|}
\hline número do grupo & material & médias em $\mathrm{kgf} / \mathrm{mm}^{2}$ \\
\hline 1 & Concise ortodôntico sem tratamento (grupo controle) & 0,263 \\
\hline 2 & ataque ácido + (adesivo $(A)+$ adesivo $(B))$ do conjunto Concise ortodôntico + Concise ortodôntico & 0,325 \\
\hline 3 & jato de óxido de alumínio + Concise ortodôntico & 0,285 \\
\hline 4 & $\begin{array}{c}\text { jato de óxido de alumínio + ataque ácido }+(\operatorname{adesivo}(A)+\text { adesivo }(B)) \text { do conjunto Concise } \\
\text { ortodôntico }+ \text { Concise ortodôntico }\end{array}$ & 0,337 \\
\hline
\end{tabular}

Tabela 5 - Médias da resistência adesiva sob esforços de cisalhamento, obtidas com a resina Transbond XT.

\begin{tabular}{ccc}
\hline número do grupo & material & médias em kgf/mm² \\
5 & Transbond XT sem tratamento (grupo controle) & 0,278 \\
7 & ataque ácido + adesivo do conjunto Transbond XT+ Transbond XT \\
8 & jato de óxido de alumínio + Transbond XT & 0,284 \\
0,322 & 0,307
\end{tabular}

Tabela 6 - Médias da resistência adesiva sob esforços de cisalhamento, obtidas com a resina restauradora Filtek Z-250.

\begin{tabular}{ccc}
\hline número do grupo & material & médias em kgf/mm² \\
9 & Filtek Z-250 sem tratamento (grupo controle) & 0,263 \\
11 & ataque ácido + adesivo Single Bond + FiltekZ-250 & 0,203 \\
12 & jato de óxido de alumínio + Filtek Z-250 & 0,269 \\
0,243 & jato de óxido de alumínio + ataque ácido + adesivo Single Bond + Filtek Z-250
\end{tabular}


te aumento aritmético, o que já representa uma tendência de aumento sob condições clínicas. Essa variação de efeito de tratamento (adesivo 6 e jateamento grupo 3) é também responsável pela significância de interação entre os fatores ou falta de homogeneidade de comportamento. Assim, pode-se inferir, à semelhança do grupo da resina Concise ortodôntico, que todos os tratamentos estudados realizados nas bases, para a resina composta Transbond XT, melhoraram a adesividade na interface braquete/resina.

Os valores médios dos grupos da resina Filtek Z-250 (Tab. 6) demonstraram que nenhum tratamento realizado na base dos braquetes aumentou a resistência adesiva, ao contrário, até a diminuiu. A comparação intragrupo da resina Filtek Z-250 pode ser observada na tabela 6 , onde o sub-grupo 9 , sem tratamento na base, foi superior estatisticamente em comparação aos grupos 10 e 12, que receberam tratamento na base. Esse resultado indica que o tratamento com adesivo Single Bond na base, para utilização da resina Filtek Z-250, ao invés de aumentar, diminui a resistência adesiva na interface resina/braquete.

Provavelmente, isto ocorre porque o adesivo Single Bond tem como característica e finalidade específica promover adesão em dentina e esmalte dentário, e não em metal, o que o difere dos outros adesivos utilizados nesta pesquisa. Talvez a composição diferente dos adesivos e/ou as diferenças de valores da sua acidez $(\mathrm{PH})$ tenha, do mesmo modo, influenciado nas uniões adesivas resina/ adesivo/braquetes. Os valores menores encontrados nesta pesquisa, quando da utilização do adesivo Single Bond (composto por: HEMA 2-hidroxietilmetacrilato e acrilatos), podem também ser devidos ao $\mathrm{PH}$ ácido do material ${ }^{13}$, que provoca a inibição da fotopolimerização das camadas superficiais das resinas compostas e, conseqüentemente, interfere na qualidade de união adesivo/resina, fato descrito também por outros autores ${ }^{8}$.

Verifica-se que o grupo 11, que recebeu somente o jateamento com óxido de alumínio, tam- bém não aumentou significantemente a força de adesão na interface estudada, não tendo, porém, prejudicado a adesão. Assim, pode-se concluir, para o grupo Filtek Z-250, que os tratamentos aplicados não promoveram aumento significativo estatisticamente, ficando a impressão de que o adesivo Single Bond não deve ser empregado com a resina Filtek Z-250 em superfícies metálicas, tratadas com jatos de alumínio ou não.

Após o deslocamento, ruptura ou fratura, os corpos-de-prova e os braquetes foram examinados com lupa (10 vezes de aumento) para definir o local e/ou tipo de fratura ocorrida, permitindo determinar o índice de adesivo remanescente e locais onde ocorreram as fraturas: interface resina/ braquete ou falha coesiva do material. As porcentagens foram as seguintes:

- Grupo 1: 100\% de fraturas adesivas;

- Grupo 2: 100\% de fraturas adesivas;

- Grupo 3: 60\% de fraturas adesivas e 40\% de fraturas coesivas;

- Grupo 4: 60\% de fraturas adesivas e 40\% de fraturas coesivas;

- Grupo 5: 100\% de fraturas adesivas;

- Grupo 6: 90\% de fraturas adesivas e 10\% de fraturas coesivas;

- Grupo 7: 100\% de fraturas adesivas;

- Grupo 8: 70\% de fraturas adesivas e 30\% de fraturas coesivas;

- Grupo 9: 100\% de fraturas adesivas;

- Grupo 10: 90\% de fraturas adesivas e 10\% de fraturas coesivas;

- Grupo 11:90\% de fraturas adesivas e 10\% de fraturas coesivas;

- Grupo 12: 90\% de fraturas adesivas e 10\% de fraturas coesivas.

Como observado, apenas 15 espécimes, de um total de 120, sofreram fraturas coesivas. Essa ocorrência, $12,5 \%$, pode ser considerada mínima, indicando que os ensaios foram bem controlados e realizados em função de uma metodologia que pode ser considerada confiável para avaliar a força de união resina/braquetes. 
As fraturas coesivas ocorrem porque os pontos de solda reduzem a área de retenção, o que é crítico em bases pequenas, além de apresentarem um potencial de fratura no local da colagem; os pontos de solda não apenas diminuem a área disponível para retenção, como também concentram esforços, os quais podem iniciar fratura na interface acessório/resina.

\section{CONCLUSÕES}

De acordo com a metodologia empregada e após análise e discussão dos resultados obtidos, chegou-se às seguintes conclusões.

\section{Em relação à metodologia empregada}

- A ocorrência de $12,5 \%$ de fraturas coesivas pode ser considerada mínima, indicando que a metodologia empregada pode ser considerada confiável para avaliar especificamente a força de união da interface resina/braquete.

\section{Em relação aos tipos e materiais empregados}

- As resinas compostas Concise ortodôntico Transbond XT e Filtek Z-250 apresentaram valores similares de resistência adesiva sob esforços de cisalhamento, quando aplicadas nas bases metálicas dos braquetes Abzil, sem nenhum tratamento prévio (grupos controle).

\section{Em relação aos tipos de tratamentos na base dos braquetes}

- Concise ortodôntico: os tratamentos que incluíam a aplicação do adesivo específico, com ou sem jateamento com óxido de alumínio na base do braquete, foram mais efetivos para a resina composta Concise ortodôntico, quando comparados ao seu grupo controle.

- Transbond XT: os tratamentos que incluíam o jateamento com óxido de alumínio associado ou não ao adesivo específico na base do braquete, foram mais efetivos estatisticamente para a resina composta Transbond XT, quando comparados ao seu grupo controle.
- A resina composta Filtek Z-250, quando utilizado o adesivo Single Bond na base do braquete, associado ou não ao jateamento com óxido de alumínio, promoveu uma queda dos valores de resistência ao cisalhamento.

- De maneira geral, todos os tratamentos empregados melhoraram a adesão da resina composta à base dos braquetes, à exceção dos grupos que utilizaram o adesivo Single Bond.

- O tratamento com jateamento com óxido de alumínio na base dos braquetes melhorou todos os valores de adesividade, na interface resina/braquete, para todos os materiais de colagem utilizados nesta pesquisa.
Enviado em: outubro de 2004 Revisado e aceito: março de 2005 


\title{
Comparative study of the shear bond strength of the resin/bracket interface, using three different resin composites and three different treatments in the base of the bracket
}

\begin{abstract}
Aim: Considering that the adhesion between the brackets and the resin is chemo-mechanical, the aim of this study was to investigate: 1) the efficacy of the method used to assess the bond strength at the resin/bracket interface; 2) the shear bond strength of the resin/bracket interface using three resin composites (Concise orthodontic, Transbond XT and Filtek Z-250); 3) the effect of sandblasting of the base of the metallic bracket with aluminum oxide, associated or not to the application of adhesive. Methods: Shear bond strength was carried out at a universal testing machine. Data were submitted to analysis of variance and Tukey multiple comparison test. Results and Conclusions: The occurrence of $12.5 \%$ of cohesive failures may be considered minimal, thus indicating that the method is appropriate to assess the bond strength at the resin/bracket interface. The different resin composites (Concise Orthodontic, Transbond XT and Filtek Z-250) used for bonding without any previous surface treatment of the bracket (control groups) resulted in similar shear bond strength. The application of adhesive, with or without previous sandblasting of the base of the bracket, improved the shear bond strength for the Concise orthodontic resin composite, when compared to its control group. Sandblasting of the bracket, regardless of the combined use of adhesive, was statistically superior for the Transbond XT resin composite when compared to its control group. The application of the adhesive Single Bond in the base of the bracket, with or without previous sandblasting, promoted a decrease in the shear bond strength for the Filtek Z-250 resin composite. Sandblasting of the metallic bracket with aluminum oxide improved the adhesion at the resin/bracket interface for all the resin composites used in this study.
\end{abstract}

Key words: Shear bond strength. Resin composites. Bonding.

\section{REFERÊNCIAS}

1. ASHCRAFT, D. B.; STALEY, R. N.; JAKOBSEN, J. R. Fluoride release and shear bond strengths of three light-cured glass ionomer cements. Am. J. Orthod. Dentofacial Orthop., St. Louis, v. 111, no. 3, p. 260-265, Mar. 1997.

2. BELTRAMI, L. E. R.; FREITAS, C. A.; MARTINS, D. R. Braquetes com sulcos retentivos na base, colados clinicamente e removidos em laboratório por testes de tração, cisalhamento e torção. Ortodontia, São Paulo, v. 29, n. 2, p. 27-39, maio/ago. 1996.

3. BISHARA, S. E. et al. Effects of modifying the adhesive composition on the bond strength of orthodontic brackets. Angle Orthod., Appleton, v. 72, no. 5, p. 464-467, Oct. 2002.

4. BRYANT, S. et al. Tensile bond strength of orthodontic bonding resins and attachments to etched enamel. Am. J. Orthod., St. Louis, v. 92, no. 3, p. 225-231, Sept. 1987.

5. BUONOCORE, M. G. A simple method of increasing the adhesion of acrylic filling materials to enamel surfaces. J. Dent. Res., Alexandria, v. 34, no. 6, p. 849-853, Dec. 1955

6. FAJEN, V. B. et al. An in vitro evaluation of bond strength of three glass ionomer cements. Am. J. Orthod. Dentofacial Orthop., St. Louis, v. 97, no. 4, p. 316-322, Apr. 1990.

7. FARIA, E. M.; MONDELLI, J. Influência dos pinos dentinários na resistência adesiva de restaurações em dentes anteriores faturados. 1998. 78 f. Dissertação (Mestrado em Odontologia)-Faculdade de Odontologia de Bauru, Universidade de São Paulo, Bauru, 1998.

8. FRANCO, E. B. et al. Evaluation of compatibility between different types of adhesives and dual cured resin cement. J. Adhes. Dent., v. 4, no. 4, p. 271-275, Winter 2002.

9. KIDD, W. L. et al. Tongue and lip forces during deglution with and without an anterior open bite. J. Dent. Res., Alexandria, v. 42, no. 3, p. 858-62, May/June 1963.

10. MONDELLI, J. et al. Estética e cosmética em clínica integrada restauradora. São Paulo: Quintessence, 2003.
11. MONDELLI, J.; PEREIRA, M. A.; MONDELLI, R. F. L. Etiologia e tratamento dos diastemas dentários. Biodonto, v. 1, n. 3, p. 9-104, maio/jun. 2003.

12. PHILLIPS, H. W. Bonding first molars. J. Clin. Orthod., Boulder, v. 20, no. 5, p. 320-323, May 1986.

13. SANARES, A. N. E. et al. Adverse surface interactions between one-bottle light-cured adhesives and chemical-cured composites. Dent. Mater., Copenhagen, v. 17, p. 542-546, 2001.

14. SANTANNA, E. F. et al. Bonding brackets to porcelain - in vitro study. Braz. Dent. J., Ribeirão Preto, v. 13, n. 3, p. 191196, 2002.

15. THANOS, C. E.; MUNHOLLAND, T.; CAPUTO, A. A. Adhesion of mesh-base direct-bonding brackets. Am. J. Orthod., St. Louis, v. 75, no. 4, p. 421-230, Apr. 1979.

16. VELASQUEZ, N. Z. Estudo comparativo das unioes braquete / resina / dente; braquete / resina / cobre - alumínio; braquete / resina / níquel - cromo; braquete / resina / porcelana, mediante testes de cisalhamento, utilizando as resinas Enforce e Concise. 1998. 140 f. Dissertação (Mestrado em Odontologia)Faculdade de Odontologia de Bauru, Universidade de São Paulo, Bauru, 1998.

17. WEISSER, J. I. A successful method for bonding stainless steel brackets and auxiliaries. J. Clin. Orthod., Boulder, v. 7, no. 10, p. 637-645, Oct. 1973.

Endereço para correspondência

Adriano Lia Mondelli

Praça Rodrigues de Abreu 2-38 - Centro

CEP:17.015-240, Bauru-SP

E-mail: adrianomondelli@uol.com.br 